\section{Pioglitazone mitigates inflammation in patients with overt diabetic nephropathy}

The THIAZOLIDINEDIONE pioglitazone can reduce inflammation in patients with chronic kidney disease secondary to type 2 diabetes mellitus, according to the results of a prospective, singlecenter trial. The researcher proposes that, through its anti-inflammatory effects, the drug could lessen the high risk of cardiovascular events in this population.

Men with advanced diabetic nephropathy were randomized to receive pioglitazone $(n=21)$ or the SULPHONYLUREA glipizide $(n=19)$ for 16 weeks. Levels of biomarkers of inflammation, such as white blood cell count, plasma C-reactive protein and plasma INTERLEUKIN 6 (IL-6), as well of as plasma MATRIX METALLOPROTEINASE 9-an indicator of atherosclerotic plaque stabilization-were significantly reduced after treatment with pioglitazone $(P<0.05$ for all). The $1,125 \mathrm{cells} / \mu \mathrm{l}$ reduction in white blood cell count and $58 \%$ decrease in IL-6 level in the pioglitazone group were significant even when compared with changes in these inflammation biomarkers in the glipizide group $(P=0.009$ and $P=0.001$, respectively). Levels of plasma TUMOR NECROSIS FACTOR $\alpha$ and markers of oxidative stress (plasma MALONDIALDEHYDE, plasma and urine albumin carbonyl and total protein carbonyl) did not change in response to either therapy.

Pioglitazone is a synthetic PEROXISOME PROLIFERATIVE ACTIVATED RECEPTOR $\gamma$ agonist that inhibits the expression of proinflammatory genes and reduces monocyte production of inflammatory markers such as IL-6. Subject to confirmation in large trials, pioglitazone could be used together with angiotensin-receptor blockers, statins and aspirin, to reduce cardiovascular event risk in patients with diabetic nephropathy.

Rachael Williams

Original article Agarwal R (2006) Anti-inflammatory effects of short-term pioglitazone therapy in men with advanced diabetic nephropathy. Am J Physiol Renal Physiol 290: F600-F605

\section{Detecting chronic allograft nephropathy using contrast-enhanced sonography}

Vascular remodeling in renal transplants can impair renal blood flow and lead to graft failure. Color Doppler ultrasonography (CDU) can be used to assess renal perfusion in large arteries; however, real-time contrast-enhanced sonography (RTCES) - a technique that measures microvascular perfusion using gas-filled microbubbles-might enable more detailed assessment of renal blood flow. Schwenger et al. compared the efficacy of RTCES with that of CDU in determining blood flow in the graft for the detection of chronic allograft nephropathy.

Renal transplant patients $(n=26)$ were prospectively studied for a median of 30.5 months (range 3-274 months) after transplantation. RTCES renal blood flow estimates, but not CDU estimates, were significantly correlated with serum creatinine levels $(P=0.0004)$ and glomerular filtration rates $(P=0.007)$. Compared with $\mathrm{CDU}$ estimates, RTCES estimates had higher sensitivity $(91 \%$ vs $82 \% ; P<0.05)$, specificity $(82 \%$ vs $64 \% ; P<0.05)$ and accuracy $(85 \%$ vs $73 \%$; $P<0.05)$ for detecting biopsy-confirmed chronic allograft nephropathy $(n=11)$.

The superior diagnostic power of RTCES compared with CDU might facilitate earlier detection of the changes in renal blood flow that are indicative of the onset of transplant vasculopathy, thereby permitting more timely initiation of therapeutic interventions.

Kate Matthews

Original article Schwenger V et al. (2006) Real-time contrast-enhanced sonography of renal transplant recipients predicts chronic allograft nephropathy. Am J Transplant 6: 609-615

\section{Rituximab is preferable to chemotherapy as second-line treatment for PTLD}

Reduction in immunosuppression is the initial treatment for POST-TRANSPLANT LYMPHOPROLIFERATIVE DISORDER (PTLD). Results of a small retrospective study at the University of Pennsylvania indicate that, for patients who are resistant to such an approach, rituximab-a monoclonal antibody that causes Iysis of B LYMPHOCYTES-should be the secondline treatment. Because of its high toxicity, the researchers advise that chemotherapy be reserved for those in whom rituximab fails.

The analysis included 35 PTLD patients (8 kidney, 1 combined liver and kidney, and 26 non-kidney transplant recipients) who did not respond optimally to reduction in immunosuppression or for whom this first-line

\section{GLOSSARY}

THIAZOLIDINEDIONE

A synthetic peroxisome proliferative activated receptor- $\gamma$ agonist that reduces peripheral insulin resistance, leading to a reduction in blood glucose concentration; used in the treatment of type 2 diabetes

\section{SULPHONYLUREA}

An oral hypoglycemic agent for type 2 diabetes mellitus that increases the secretion of insulin by the pancreas

INTERLEUKIN 6 (IL-6) A 184-residue polypeptide cytokine released in response to a range of stresses that stimulates proliferation and differentiation in various immune cells

\section{MATRIX}

METALLOPROTEINASE

Zinc-dependent endopeptidase capable of degrading extracellular matrix proteins; can process a number of bioactive molecules

\section{TUMOR NECROSIS} FACTOR

A multifunctional cytokine with effects on lipid metabolism, coagulation, insulin resistance and on the function of endothelial cells lining blood vessels

\section{MALONDIALDEHYDE}

An end product of lipid peroxidation and a marker of oxidative stress

\section{PEROXISOME}

PROLIFERATIVE ACTIVATED RECEPTOR $\gamma$ A transcription factor for nuclear hormone receptors that is involved in metabolic and cardiovascular regulation

POST-TRANSPLANT LYMPHOPROLIFERATIVE DISORDER (PTLD)

A disorder involving the proliferation of lymphoid tissue following transplantation

\section{B LYMPHOCYTES}

Lymphoid cells that produce antibodies to antigens on foreign agents 